\title{
Leaving in Mascot of Silence: Organizational Determinants of Employee Turnover Intentions in Mediating and Moderating Roles of Quiescent Silence and Coworker Support in a Russian Context
}

\author{
Muhammad Kashif1 ${ }^{1}$, Irina Petrovskaya² ${ }^{2}$ Sarminah Samad ${ }^{3}$, Shanika Wijenayake ${ }^{4}$
}

Submitted: 19.07.2020. Accepted: 9.03.2021

\section{Abstract}

Purpose: Drawing on social exchange theory (SET), this study explores the mediating role of quiescent silence as a link between organizational stressors and turnover intentions among Russian frontline employees (FLEs). Furthermore, we aim to investigate whether coworker support moderates the relationship between quiescent silence and turnover intentions.

Research Methods: The study is a cross-sectional survey administered among a sample of 235 FLEs employed in Russian healthcare organizations. We analyzed the data with SmartPLS version 3.0.

Findings: The results reveal that ethical conflict and abusive supervision are significantly related to quiescent silence. Quiescent silence mediates the relationship between abusive supervision, ethical conflict, and employee turnover intentions.

Managerial Implications: There is a need to provide employees with opportunities to voice their opinions. However, what is crucial is the assurance of employee privacy while motivating them to voice opinions. Managers should be more proactive in diagnosing silence.

Originality: This is the first study to explore the mediating role of quiescent silence on the relationship between organizational stressors and employee turnover intentions in a unique Russian healthcare context. The moderating role of coworker support to buffer the relationship between quiescent silence and turnover intentions is unique to this study.

Keywords: turnover intentions, abusive supervision, quiescent silence, ethical conflict, perceived injustice, Russia.

\section{JEL: D23}

\footnotetext{
1 Corresponding author, GIFT University Gujranwala, Gujranwala 52250, Pakistan, e-mail: kashif@gift.edu.pk; https://orcid.org/0000-00031274-6742.

2 Lomonsov Moscow State University Business School, 1-52 Leninskie Gory, Moscow 119234 Russia; e-mail: petrovskaya@mgubs.ru.

3 College of Business and Administration, Princess Nourah bint Abdulrahman University, Saudi Arabia, Riyadh, P0 Box 84428; e-mail: sarminahsamad@hotmail.com.

4 University of Kelaniya, University Kandy Road Kelaniya, 11600, Sri Lanka; e-mail: shanikaw@kln.ac.lk.
} 


\section{Introduction}

Frontline employees (FLEs) often quit jobs (Cho et al., 2017). This is one reason that organizations incur both direct as well as indirect costs of replacing the staff. In people-intensive service sectors, customers and frontline staff closely interact and develop a relationship. However, when FLEs quit, the emotional connection between them is lost, which also affects the quality of customer service (Kashif, Zarkada, and Thurasamy, 2017). The employees who intend to quit (i.e. have high turnover intentions) are less inclined to perform their jobs productively (Knoll, Hall, and Weigelt, 2019). Moreover, high turnover rates adversely affect corporate reputation (Ciftcioglu, 2010; Yousaf, Sanders, and Abbas, 2015). Employee turnover is an important concern among managers and has received influential academic interest (Cho et al., 2017; Kashif et al., 2017). These researchers link turnover as an outcome of destructive attitudes at work.

One of the destructive actions at work is the aggressive behavior of supervisors, conceptualized as abusive supervision. It is a non-physical hostile treatment of subordinates by their supervisors (Tepper, 2000). Abusive supervision has the potential to break trustworthy relationships and may trigger frontline employees to quit jobs (Martinko et al., 2013; Laschinger and Fida, 2014). In addition to abusive supervision, when employees perceive they are treated unfairly - which is referred to as perceived injustice during service work - negative feelings are triggered toward the organization (Pretsch et al., 2016). The ethical conflict as a perceived clash between ethical concerns, employee values, and job requirements is yet another factor highlighted in relation to employee turnover intentions (Valentine, Hollingworth, and Eidsness, 2014). There are frameworks that unify all these elements (Mannan and Kashif, 2019). The core logic to connect these issues is the coexistence of these phenomena at work. Moreover, in an organizational context with prevalent negativity, such negative disruptions are very common (Harlos and Knoll, 2018; Johnson et al., 2018). Despite these issues, employees must display positive behaviors during social interactions at work. For instance, the FLEs are expected to be vocal during service work (Cho et al., 2017).

Employee voicing is important and possible when they are comfortable and actively participate in work-related activities. However, aggressive and destructive workplace behaviors hurt active employee involvement in work (Johnson et al., 2018). Interestingly, employees cannot always respond aggressively to destructive action, e.g. when supervisors abuse employees (Lam and Xu, 2019). The supervisors are superior in authority thus employees cannot reciprocate. There is evidence that employees prefer to remain silent when humiliated by their bosses (Lam and Xu, 2019; Whiteside and 
Barclay, 2013). This defensive mental state is quiescent silence, conceptualized as an act of withholding information after facing negativity at work (Pinder and Harlos, 2001). Employee silence is not always defensive. Sometimes, employees believe voicing is useless in this organization, which forms acquiescent silence (Pinder and Harlos, 2001). In another situation, the employees act as good "secret keepers" and do not reveal corporate secrets to others (Dahling et al., 2012). This type of silence refers to pro-social silence. Finally, when employees remain silent to gain power and status, such a motive is called opportunistic silence (Knoll and van Dick, 2013). Among all these forms, quiescent silence closely links to the arousal of negative feelings at work (Mannan and Kashif, 2019). This is because quiescent silence is based on fear, understandable in a hierarchical relationship between subordinates and their bosses (Lam and $\mathrm{Xu}, 2019$ ). When employees are defensive during work, their intentions to continue with the work weaken over time and they eventually quit their jobs (Knoll and van Dick, 2013).

Notably, no organization is only toxic, so some elements always encourage employees to stay and work, despite frequent episodes of aggression (Long and Christian, 2015). Keeping abreast of this assumption, support from coworkers can bring positive work outcomes, i.e. employee productivity and retention (Shantz, Alfes, and Latham, 2016). Scholars highlight the role of coworker support as an element that can minimize stress at work (De Clercq et al., 2020). We believe that coworker support can help retain employees in an environment with prevalent aggressive behaviors. Ample research investigates aggressive behavior and its negative consequences but to disappointing results (Chung and Yang, 2017), which motivated our study.

This study contributes to the existing body of knowledge on defensive work behaviors in several ways. Keeping in view the importance of positive voicing of employees to improve service design and delivery (Schepers and Nijssen, 2018) and the recent contributions to examine quiescent silence among FLEs, we present injustice and ethical conflict in addition to abusive supervision as antecedents of quiescent silence. The injustice perception and ethical conflict are common among service professionals - but typically investigated separately (Park et al., 2017; Rainer, Schneider, and Lorenz, 2018). So far, scholars only foreground abusive supervision as an antecedent to quiescent silence (Kiewitz et al., 2016; Xu et al., 2020), while missing other organizational level variables that form antecedents of quiescent silence other than the abusive supervision itself (Wang et al., 2020). In line with this stream of research, silence is typically studied as a consequence of abusive supervision, but quiescent silence as an outcome of organizational predictors other than abusive supervision is neglected by researchers (Xu et al., 2020). The scarcity of investigations to explore predictors of quiescent silence in research is evident in recent studies that ignore quiescent silence as a form of silence 
(Wang et al., 2020). Moreover, coworker support is an important element of frontline work (Kim et al., 2017). Logically, when employees are worried at work, they tend to discuss and seek support from colleagues (Rai and Agarwal, 2018). There are studies that examine negative workplace outcomes as a consequence of aggressive workplace behaviors (Khalid et al., 2018). How support from coworkers can heal emotional damage is a question recently raised by organization science researchers (De Clercq et al., 2020).

Another contribution of this study is the unique context of healthcare organizations in Russia. The lack of feedback and initiative from the bottom levels of hierarchy form the typical problems for managers working in Russian companies (Vinokurova, Boltrukevich, and Naumov, 2017). Most line workers are convinced that management is not interested in their feedback (Vinogradova and Kozina, 2011), which can hinder positive voice among FLEs. Given the low unemployment rates reported in Moscow, employees are expected to consider labor market conditions as favorable for job switching. There are few studies conducted in Russia that examine employee turnover intent, but their core focus remains in associating employee satisfaction with turnover intentions (Balabanova et al., 2016). These studies conceptualize wage satisfaction, interpersonal relationships, and job satisfaction as core antecedents of employees' intentions to leave. Moreover, there is strong empirical evidence to support that aggressive behaviors at work are on the rise (Gregory et al., 2013).

Most Russian employees consider good relationships with coworkers one of the most important aspects of their jobs, especially in the service industries (Vinogradova and Kozina, 2011). However, in terms of governance and structure, most of the organizations employ an authoritative style of management that can hinder the achievement of service quality (Saari et al., 2017). Moreover, workplace aggression is found as harmful for healthcare employees, adversely affecting their on-job performances (Johnson et al., 2018). Based on the Russian context, we address the call to examine turnover intentions in a non-Western context (Mannan and Kashif, 2019; Mustafa and Ali, 2019) with a specific emphasis on predictors that are relatively novel in turnover studies as compared to the long-standing vein of research focused on e.g. job satisfaction (Balabanova et al., 2016) or job commitment (Dusek et al., 2016). Current research indicates that national culture can influence perceptions and reactions to abusive supervision. Specifically, power distance may influence the reactions to abusive supervision (Richard et al., 2018), perceived injustice (Khan, Quratulain, and Crawshaw, 2013), and the violation of ethical norms (Tian and Peterson, 2016). Therefore, Russia as a country conventionally classified as a high power distance culture (Hofstede, Hofstede, and Minkov, 2005) provides an appropriate setting to explore the relationships proposed 
in this study. The empirical and contextual issues qualify Russia and the healthcare context worthy of investigation.

The article proceeds with a theoretical framework and hypotheses development section, in which we present how SET explains the proposed relationships. Next, we present our research methods to explicate details of the sampling frame, issues of sample selection, approaches to data collection, and the management of social biases. This leads to the results section, in which we detail the findings of this study. The ensuing discussion section highlights the theoretical explanation of the findings. Finally, the limitations and future research directions section describes the limitations of this study, which are closely linked to future research directions.

\section{Theoretical Framework and Hypotheses Development}

The Social Exchange Theory (SET) inspires the framework of this study. One of the core assumptions of SET is that relationships are reciprocal (Cook et al., 2013; Homans, 1958). The theory posits a reciprocal relationship between individuals based on the expected benefits and returns since each entity within the exchange bears a certain investment while building or maintaining a relationship (Serenko and Bontis, 2016). Individuals react with aggression when benefits in their social exchange do not meet their expectations (Homans, 1958). The prosocial behaviors at work are reciprocal and are performed as a consequence of fair treatment (Serenko and Bontis, 2016). Based on this premise, we believe that employees will remain silent in response to abusive supervision, perceived injustice, and ethical conflict, which may drive turnover (Cho et al., 2017). There is evidence to state that workplace bullying is reciprocated with silence (Rai and Agarwal, 2018). The employees avoid interactions and remain silent when bullied at work. In another reciprocal arrangement, employee silence is theorized as an outcome of abusive supervision at work (Khalid et al., 2018).

More recently, quiescent silence is proposed to be an outcome of leader Machiavellianism (Erkutlu and Chafra, 2019). All these studies posit quiescent silence is a reciprocal arrangement between perceived unfairness at work and employee silence. The employees as part of a hierarchy cannot become aggressive in response to aggression and negativity at work. Thus, they prefer to remain silent. On the other hand, coworker support may reduce the turnover intentions arising from these negative work practices. Coworker support is a reciprocal arrangement, which is found to strengthen employee socialization at work (Akgunduz and Eryilmaz, 2018) while contributing to employee well-being (Kim, Moon, and Shin, 2018). Coworker support can strengthen employee per- 
ceptions of positivity at work. There are examples that show coworker support strengthens pro-environmental attitude among employees (Paillé et al., 2016). Coworker support is a powerful medium to establish innovative behaviors at work (Rehman et al., 2019). All these studies position coworker support as a form of reciprocity at work. This entails that coworker support has the potential to establish a constructive work environment while bringing positive attitudes. By investigating these relationships grounded in SET, we enrich the literature by stressing the empirical significance of defensive mechanisms in service work, which is particularly ignored within SET literature (Serenko and Bontis, 2016).

\section{Abusive Supervision and Quiescent Silence}

Abusive supervision refers to the angry, rude, and hypocritical behaviors of supervisors toward FLEs (Harris, Harvey, and Kacmar, 2011; Kiewitz et al., 2016). An abusive behavior, once experienced, arouses a feeling of disappointment among individuals (Ju et al., 2018). In response to abuse, the FLEs may decide to remain protective (i.e. silent; Fast, Burris, and Bartel, 2014). This way it adversely affects their in-role performance (Burke and Cooper, 2013). Keeping abreast of this discussion and basing on the assumptions of SET, we envision quiescent silence as a behavioral response (i.e. visible to others) to abusive supervision. Recent studies treat silence as a behavior (Harlos and Knoll, 2018): employees would like to remain silent in response to aggression. Since it is an avoiding yet defensive approach that cannot be assessed by the supervisor, it limits the chances that any further action can be taken against employees (Wang et al., 2020).

Abusive supervision may produce different reactions in different cultures. Furthermore, there is a dearth of studies that investigate abusive supervision in a non-Western context (Mannan and Kashif, 2019; Mustafa and Ali, 2019). However, most studies of abusive supervision are based on US samples (Tepper, 2007). The power distance in Russia is considerably higher than in the USA, which makes the context of our study unique (Hofstede et al., 2005). The application of abusive supervision is unique in Russia. In a recent survey (Balabanova et al., 2016), over 60\% of respondents demonstrated turnover intentions in response to abusive managerial behavior, which implies that abusive supervision is not a positive or accepted norm of behavior for Russian employees. Therefore, we expect that abusive supervision will be conducive to quiescent silence and propose the following hypothesis:

H1: Abusive supervision positively relates to quiescent silence among Russian FLEs. 


\section{Perceived Injustice and Quiescent Silence}

Perceived injustice is a feeling of discrepancy found in different treatment of individuals at work (Scott et al., 2016). It refers to a mental state in which employees feel isolated and ignored in comparison to others (Law, 2007; Scott et al., 2013). Employee engagement at the frontline is important and is partly dependent on perceived justice (Zeidan and Itani, 2020). When employees feel treated unfairly, their rationality is affected, and emotions dominate. In such situations, the probability of making a wrong decision gradually increases and may produce turnover intentions (Long and Christian, 2015). Moreover, when employees perceive treatment as unjust, they become psychologically detached and, in this way, incline toward counterproductive work behaviors (Cohen and Diamant, 2017). In our case, this psychological detachment is quiescent silence, a reciprocal response to injustice perceptions in a SET perspective.

Perceived injustice is closely associated with abusive supervision. A study of Russian working adults indicates that unfair treatment is one of the components of abusive supervision in Russia (Balabanova et al., 2016). However, the present study treats perceived injustice as a separate construct, based on the effect of perceived injustice on turnover intentions found in many studies in different settings (Reknes, Glambek, and Einarsen, 2020). Thus, we hypothesize:

H2: Perceived injustice positively relates to quiescent silence among Russian FLEs.

\section{Ethical Conflict and Quiescent Silence}

Employees have a belief system that comprises thoughts and personal values they continuously compare to the organizational value system. The importance of ethics and dignity at work is highlighted by researchers (Zawadzki, 2018). The situation in which employees notice a discrepancy between their ethical beliefs and organizational ethical values and practices is referred to as ethical conflict (Kammeyer-Mueller et al., 2012). This perceived discrepancy may trigger negative deviance (Shantz and Booth, 2014). Negative events at work hurt employees' self-confidence, affecting their performance (Fast et al., 2014) and ultimately their motivation to voice opinions as they focus on surviving and defending themselves. This way employees might reciprocate an ethical conflict with quiescent silence, a product of a defensive mental state (Park et al., 2017). 
There are indications that culture - especially power distance - may affect how people perceive and react to violations of ethical norms by their superiors. While the prevailing assumption is that in high power distance cultures employees are less inclined to question their supervisors' morals (Shao et al., 2013), empirical evidence indicates that in the case of ethical violations they may also bring their concerns outside the organization (MacNab et al., 2007). However, most empirical studies deal with cultural influences that focus on ethical violations and ethical leadership, while employee reactions to ethical conflicts remain underresearched. Based on the theoretical framework of the present study, we hypothesize:

H3: Ethical conflict positively relates to quiescent silence among Russian FLEs.

\section{Quiescent Silence and Turnover Intentions}

Quiescent silence as an antecedent of turnover intentions is gaining increasing research interest (Vemuri, 2019). There is evidence that it can indeed be conducive to the intention to quit (Mannan and Kashif, 2019). Russia and specifically Moscow, which was the setting of the present study, provide an appropriate context to investigate this relationship. On the one hand, low unemployment rates (Rosstat, 2020) may be conducive to the high level of turnover intentions. However, we should investigate whether quiescent silence significantly affects these intentions. The lack of voice - i.e. the lack of feedback and initiative from the bottom levels of hierarchy - is a typical problem for Russian companies (Vinokurova et al., 2017). Most line workers are convinced that management is not interested in their information inputs or afraid to take responsibility. This type of silence is not conducive to turnover intentions, but we cannot completely classify it as a defensive reaction. Based on previous conceptualizations of silence (Vemuri, 2019), we expect that even in this complex context, quiescent silence as a specific defensive mechanism will relate to turnover intentions. In this regard, we hypothesize the following:

H4: Quiescent silence positively relates to turnover intentions among Russian FLEs.

\section{Mediation of Quiescent Silence}

Quiescent silence is a motive conceptualized as a defensive mechanism that is used by employees as a tool to survive in challenging/threatening situations (Fast et al., 2014; Lam and $\mathrm{Xu}, 2019)$. Scholars study the relationship between abusive behaviors and 
turnover intent (Kiewitz et al., 2016), but they insufficiently examine the defensive mechanisms intervening in these relationships (Lam and Xu, 2019). The researchers position quiescent silence as a mediator between perceived injustice and negative outcomes (Whiteside and Barclay, 2013). The results reveal that perceptions of injustice drain employees emotionally to a mental state in which they might hold some useful information but prefer remaining silent. Such behavior is the outcome of psychological withdrawal. There is evidence that silence behaviors trigger employee turnover intentions (Jensen, Patel, and Messersmith, 2013) and other negative work outcomes. Notably, researchers suggest including more organizational-level factors to enrich our understanding of the reasons employees leave organizations, along with boundary conditions such as ethical climate and abusive behaviors (Morrison, 2014). In this regard, we include in this study abusive supervision and ethical conflict (besides perceived injustice) as antecedents of quiescent silence by enriching the existing frameworks (Balabanova et al., 2016; Whiteside and Barclay, 2013).

Employee relations at work are reciprocal, and based on assumptions of SET, employees will behave in the way they are being treated (Hogreve et al., 2017). This entails that employees will demonstrate positive gestures in cases they perceive fair treatment, and vice versa. During service work, behaviors are socially visible. Notably, abusive behavior and unfair treatment by bosses might be perceived as an insult and has the potential to drive employees toward a state of psychological withdrawal (Howard and Cordes, 2010). Once they are in such a mental state, they try their best to save their ego and self-esteem (Fast et al., 2014). Quiescent silence is just one way to protect self-esteem and ego during service work. Hence, employees prefer to remain silent. Above all, the assurance of personal safety and security is an important motive to work (Maslow, 1954).

Quiescent silence is a mediator in different models that connect a range of organizational antecedents, e.g. overall justice (Whiteside and Barclay, 2012) or punishment (Dedahanov et al., 2016), to different employee outcomes, e.g. emotional exhaustion, stress, or psychological and physical withdrawal. Extending the logic that connects abusive supervision, perceived injustice, and ethical conflict to quiescent silence - and quiescent silence to turnover intentions - and following the model tested by Mannan and Kashif (2019), we hypothesize:

H5: Quiescent silence among FLEs significantly mediates the relationship between abusive supervision and turnover intentions among Russian FLEs.

H6: Quiescent silence among FLEs significantly mediates the relationship between perceived injustice and turnover intentions among Russian FLEs. 
H7: Quiescent Silence among FLEs significantly mediates the relationship between ethical conflict and turnover intentions among Russian FLEs.

\section{Moderation of Coworker Support}

In an environment full of anxiety and stress, workers need positive support from peers and supervisors to perform challenging tasks (Halbesleben, 2012). There is evidence that individuals who receive support from their peers feel social recognition, which makes them less sensitive to all the injustice they perceive at work (Hüffmeier and Hertel, 2011). Moreover, coworker support is a source of identity formation among individuals and helps them to form friendships at work (McGuire, 2007; Halbesleben, 2012; Kim et al., 2017). This way, peers at work help each other (e.g. in-role and extrarole behaviors) and exchange emotions such as love and affection, in line with the SET framework. Coworker support is also recently positioned as a stress-reducing mechanism (De Clercq et al., 2020), which can reduce turnover intentions. Indeed, in a recent study (De Clercq et al., 2020) coworker support is found to reduce turnover intentions. Moreover, coworker support is found to moderate the effects of abusive supervision on turnover intentions in Ecuador, a culture with a very high power distance (Xu et al., 2018). Most Russian employees consider good relationships with coworkers and coworker support one of the most important aspects of their jobs, especially in the service industries (Dusek et al., 2016). Thus, we hypothesize:

H8: Perceived coworker support moderates the relationship between quiescent silence and turnover intentions among Russian FLEs such that this relationship is stronger when perceived coworker support is high.

\section{Figure 1. Theoretical Framework}

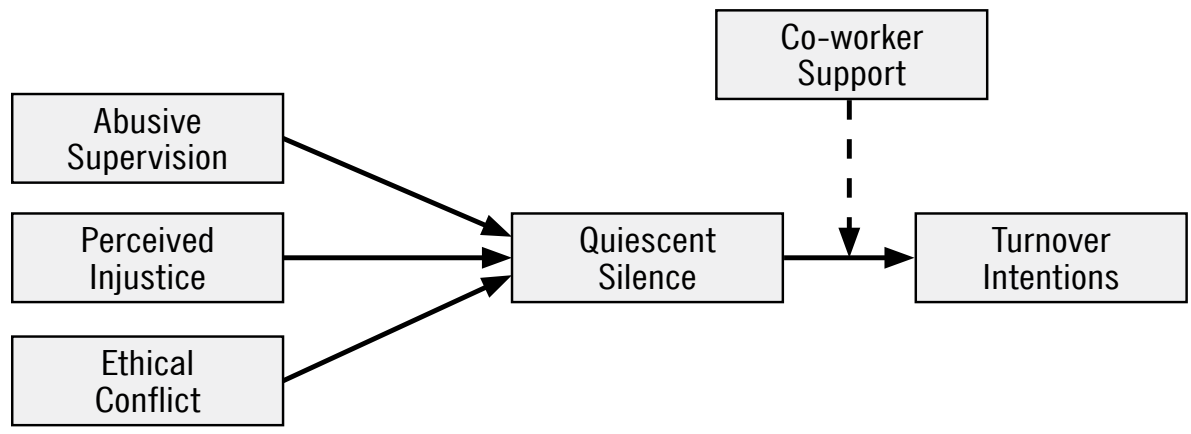

Source: own elaboration. 


\section{Research Methods}

\section{Sampling and Data Collection}

We collected data for this study from FLEs who work in a private healthcare company that operates a chain of polyclinics in Moscow, Russia. Healthcare is a setting prone to the destructive effects of employee silence (Tangirala and Ramanujam, 2008), especially because healthcare FLEs are key to the positive customer experience and the perception of service quality (Bondarouk, Bos-Nehles, and Hesselink, 2016). Before data collection, we sought ethical approvals from the human relations department of the company. A total of 262 paper-and-pencil questionnaires were distributed at the company's selected worksites (11 in total) to all the frontline employees (nurses, therapists, technicians, and receptionists). Given the sensitive nature of the questions, the introduction to the questionnaire informed the respondents that the study is conducted for academic purposes only and the research team guarantees the anonymity of their responses was guaranteed. The employees completed anonymous questionnaires and then returned them in sealed envelopes to the researchers. This procedure excluded any interaction with company management and thus assured the respondents that participation in the study will not affect their relationship with the employer. In total, we received 262 questionnaires, with 27 incomplete questionnaires to be discarded, thus forming 235 questionnaires retained for data analysis, with a response rate of $90 \%$.

\section{Measures}

We used the Likert scale ranging from 1 (strongly disagree) to 5 (strongly agree) to measure employee perceptions against all the constructs.

Abusive Supervision (AS) was measured on a six-item scale developed by Harris et al. (Harris et al., 2011). The sample item was "My supervisor is rude to me.” The Cronbach alpha for this scale was .90. Perceived Injustice (PI) was measured on a 10-item perceived injustice scale used by Law (Law, 2007). The sample item was "I often feel that I deserve better than what I have now." The Cronbach alpha reported in recently held studies for this scale was 0.93 (Mannan and Kashif, 2019). Ethical Conflict (EC) was measured on a four-item scale designed by Shafer (Shafer, 2002). The sample item was "I have been pressurized to go against the interest of a customer or a client to protect my boss." The Cronbach alpha reported for this measure in the original study was 0.77 . Quiescent Silence (QS) was measured on a five-item scale (Brinsfield, Edwards, and Greenberg, 2009). The sample item was "I frequently remain silent at work due to fear of retaliation.” The Cronbach alpha for this scale reported in recently held studies was 0.86. The Turnover Intentions (TI) was measured on a three-item scale (Blau, 2000). 
The sample item was "I will leave this job as soon as possible." The Cronbach alpha reported for this scale was 0.96. Finally, Coworker Support (CS) was measured on a 10-item scale (Ducharme and Martin, 2000). The sample item was "My coworkers are friendly to me.” The Cronbach alpha for this scale was 0.85 .

We categorized respondents based on their age and gender. Among the respondents, $85.5 \%$ were women, while $41 \%$ were aged between $41-50$ years. Table 1 presents further details about the sample.

Table 1. Sample demographics

\section{Frequency}

\section{Gender}

Male

Female

Age

21-30

$31-40$

41-50

51 and above
34

201

27

48

98

62
Percentage

$14.5 \%$

$85.5 \%$

$11.5 \%$

$20.4 \%$

$41.7 \%$

$26.4 \%$

Source: own elaboration.

\section{Common Method Variance}

We tested for Harman's single factor to assess common method variance (CMV) due to data collected from a single source. There is a $30.24 \%$ variance due to un-rotated loadings. The highest inter-construct correlation found was recorded at 0.740 (see Table 2), substantially lower than the recommended value of 0.90 (Bagozzi, Yi, and Phillips, 1991). Therefore, CMV was not a problem in this study. Confirmatory factor analysis (CFA) established the measurement model, which then led to path analysis testing the hypotheses. 
Table 2. Discriminant validity

\begin{tabular}{|c|c|c|c|c|c|c|c|c|}
\hline & & & & & & & & \\
\hline & & & 1 & 2 & 3 & 4 & 5 & 6 \\
\hline & Mean & SD & AS & PI & EC & QS & cWS & $\mathrm{TI}$ \\
\hline Abusive Supervision (AS) & 1.24 & 0.59 & 0.817 & & & & & \\
\hline Perceived Injustice (PI) & 2.72 & 1.12 & 0.138 & 0.751 & & & & \\
\hline Ethical Conflict (EC) & 2.04 & 1.05 & 0.441 & 0.431 & 0.828 & & & \\
\hline Quiescent Silence (QS) & 2.30 & 1.03 & 0.377 & 0.201 & 0.688 & 0.739 & & \\
\hline Co-worker Support (CWS) & 4.07 & 0.88 & 0.092 & -0.069 & 0.162 & -0.002 & 0.766 & \\
\hline Turnover Intentions (TI) & 1.43 & 0.77 & 0.704 & 0.350 & 0.533 & 0.521 & -0.013 & 0.898 \\
\hline
\end{tabular}

Note: values on the diagonal (italicised) represent the square root of the average variance extracted, while the off diagonals are correlations.

Source: own elaboration.

\section{Data Analysis and Results}

Confirmatory factor analysis was performed to test the model fit based on convergent and discriminant validity (Gerbing and Anderson, 1988). Results of model fit obtained through the CFA show a good fit: $-2=791.211 \mathrm{df}$. $=260, \mathrm{p}<.01,-2 / \mathrm{df}=3.043$, root mean square error of approximation [RMSEA] $=0.061$ and comparative fit index [CFI] $=0.901$. Out of the six constructs of the study, the average variance extracted (AVE) was greater than 0.5 for all the constructs, which confirms the model's convergent validity (Hair et al., 2014). The composite reliability (CR) is greater than 0.7 for all the constructs. Table 3 illustrates the AVE and CR values of all the constructs with factor loadings. A comparison of the square root of AVE with correlations between the six constructs assured discriminant validity. The cross-loadings were all higher than 0.1, as recommended (Hair et al., 2014), thus confirming the discriminant validity of the model.

\section{Structural Model Analysis}

The structural model tested eight hypotheses through direct, mediating, and moderating relationships. These results supported model fit and are presented in tables IV, V, and VI: $-2=2.328$, df. $=1, \mathrm{p}<.01,-2 / \mathrm{df}=2.328$, root mean square error of approximation $[\mathrm{RMSEA}]=0.075$ and comparative fit index $[\mathrm{CFI}]=0.997$. 
Table 3. Measurement model

\begin{tabular}{|c|c|c|c|c|}
\hline Construct & Item & Loadings & AVE & C.R \\
\hline \multirow{5}{*}{ Abusive supervision } & AS1 & 0.699 & 0.667 & 0.907 \\
\hline & AS2 & 0.832 & & \\
\hline & AS3 & 0.929 & & \\
\hline & AS4 & 0.663 & & \\
\hline & AS5 & 0.924 & & \\
\hline \multirow{5}{*}{ Perceived Injustice } & PI1 & 0.839 & 0.564 & 0.865 \\
\hline & $\mathrm{PI} 2$ & 0.836 & & \\
\hline & $\mathrm{PI} 3$ & 0.717 & & \\
\hline & $\mathrm{PI} 4$ & 0.612 & & \\
\hline & $\mathrm{PI} 5$ & 0.730 & & \\
\hline \multirow{3}{*}{ Ethical Conflict } & EC1 & 0.965 & 0.687 & 0.866 \\
\hline & EC2 & 0.729 & & \\
\hline & EC3 & 0.774 & & \\
\hline \multirow{3}{*}{ Quiescent Silence } & QS1 & 0.517 & 0.547 & 0.775 \\
\hline & QS2 & 0.920 & & \\
\hline & QS3 & 0.727 & & \\
\hline \multirow{6}{*}{ Co-worker Support } & CWS1 & 0.659 & 0.588 & 0.894 \\
\hline & CWS2 & 0.623 & & \\
\hline & CWS3 & 0.813 & & \\
\hline & CWS4 & 0.865 & & \\
\hline & CWS5 & 0.840 & & \\
\hline & CWS6 & 0.772 & & \\
\hline \multirow{3}{*}{ Turnover Intentions } & TI1 & 0.955 & 0.808 & 0.926 \\
\hline & $\mathrm{TI} 2$ & 0.946 & & \\
\hline & $\mathrm{TI} 3$ & 0.787 & & \\
\hline
\end{tabular}

Notes: AVE - average variance extracted; $C R$ - composite reliability. The italicised cells indicate the constructs used. Source: own elaboration. 
Table 4 presents the direct effects. The relationship between Abusive Supervision and Quiescent Silence was 0.257 ( $\mathrm{p}<.05)$, which indicated that Abusive Supervision significantly influences Quiescent Silence, thus supporting H1. With a corresponding estimate of -0.027 ( $p$ >.05), H2 was not supported. This indicated that the hypothesized relationship between Perceived Injustice and Quiescent Silence was not significant. The estimate for a relationship between Ethical Conflict and Quiescent Silence was 0.508 ( $\mathrm{p}<.05$ ). This indicated that Ethical Conflict significantly influences Quiescent Silence, which supports H3. The estimate for a relationship between Quiescent Silence and Turnover Intentions was $0.098(\mathrm{p}<.05)$. This indicated that Quiescent Silence significantly influences Turnover Intentions, thus supporting H4.

Table 4. Hypotheses testing

\begin{tabular}{|l|l|l|l|l|l|}
\hline Hypothesis & \multicolumn{1}{|c|}{ Relationship } & $\begin{array}{c}\text { Standardized } \\
\text { Coefficients }\end{array}$ & SE & P value & Decision \\
\hline H1 & $\begin{array}{l}\text { Abusive Supervision } \rightarrow \text { Quiescent } \\
\text { Silence }\end{array}$ & 0.257 & 0.104 & 0.014 & Supported \\
\hline H2 & $\begin{array}{l}\text { Perceived Injustice } \rightarrow \text { Quiescent } \\
\text { Silence }\end{array}$ & -0.027 & 0.053 & 0.612 & $\begin{array}{l}\text { Not } \\
\text { Supported }\end{array}$ \\
\hline H3 & $\begin{array}{l}\text { Ethical Conflict } \rightarrow \text { Quiescent } \\
\text { Silence }\end{array}$ & 0.508 & 0.062 & 0.000 & Supported \\
\hline H4 & $\begin{array}{l}\text { Quiescent Silence } \rightarrow \text { Turnover } \\
\text { Intentions }\end{array}$ & 0.101 & 0.039 & 0.011 & Supported \\
\hline
\end{tabular}

Source: own elaboration.

We used bootstrapping to test for mediation (Hair et al., 2014) by employing a standardized effect approach. The confidence intervals indicated the significance of the mediating impact. Table 5 effect size, which determines the size of the mediation.

Table 5. Mediation effect of Quiescent Silence

\begin{tabular}{|c|c|c|c|c|c|c|}
\hline \multirow{2}{*}{ Hypothesis } & $\begin{array}{c}\text { Direct } \\
\text { Effect }\end{array}$ & \multicolumn{3}{|c|}{ Indirect Effect } & $\begin{array}{c}\text { Effect } \\
\text { Size }\end{array}$ & Decision \\
\hline $\mathrm{H} 5: \mathrm{AS} \rightarrow \mathrm{QS} \rightarrow \mathrm{TI}$ & $0.488^{*}$ & $0.020^{*}$ & 0.004 & 0.049 & 0.026 & Supported \\
\hline $\mathrm{H} 6 \mathrm{PI} \rightarrow \mathrm{QS} \rightarrow \mathrm{TI}$ & $0.133^{\star *}$ & -0.004 & -0.021 & 0.006 & 0.005 & $\begin{array}{l}\text { Not } \\
\text { Supported }\end{array}$ \\
\hline $\mathrm{H7}: \mathrm{EC} \rightarrow \mathrm{QS} \rightarrow \mathrm{TI}$ & 0.158 & $0.070 *$ & 0.022 & 0.136 & 0.091 & Supported \\
\hline
\end{tabular}

Source: own elaboration. 
Table 6 shows results of the moderating impact (based on standardized values) of Coworker Support between Quiescent Silence and Turnover Intentions. We calculated the product of the two standardized variables as a separate variable named Interaction. We added this dummy variable to the path diagram as an exogenous variable. The results (Figure 2) revealed a significant moderating effect with both QS $(0.101, \mathrm{p}<$ $.05)$ and Interaction $(0.065, \mathrm{p}<.05)$ on TI, thus supporting H8.

Table 6. Moderation effect of Co-worker Support

\begin{tabular}{|l|l|c|c|c|}
\hline Hypothesis & \multicolumn{1}{|c|}{ Relationship } & QS & Interaction & Decision \\
\hline & Quiescent Silence $\rightarrow$ Co-Worker & $\begin{array}{c}0.101 \\
(0.011)\end{array}$ & $\begin{array}{c}0.065 \\
(0.050)\end{array}$ & Supported \\
\hline
\end{tabular}

Source: own elaboration.

Figure 2. Moderating effect of Co-worker Support

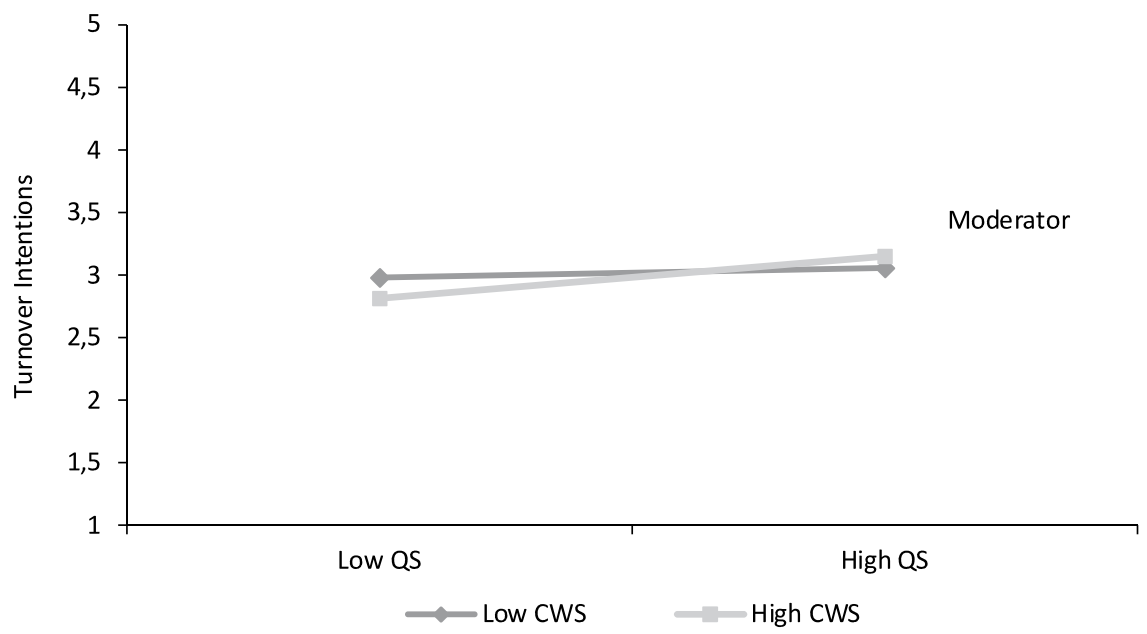

Source: own elaboration.

The $\mathrm{R}^{2}$ value was 0.567 and indicated that all five predictors explained $56.7 \%$ of the variance in Turnover Intentions. The findings of data analysis support six hypotheses. We present the Empirical Model of the study in Figure 3. 
Figure 3. Empirical model of the study

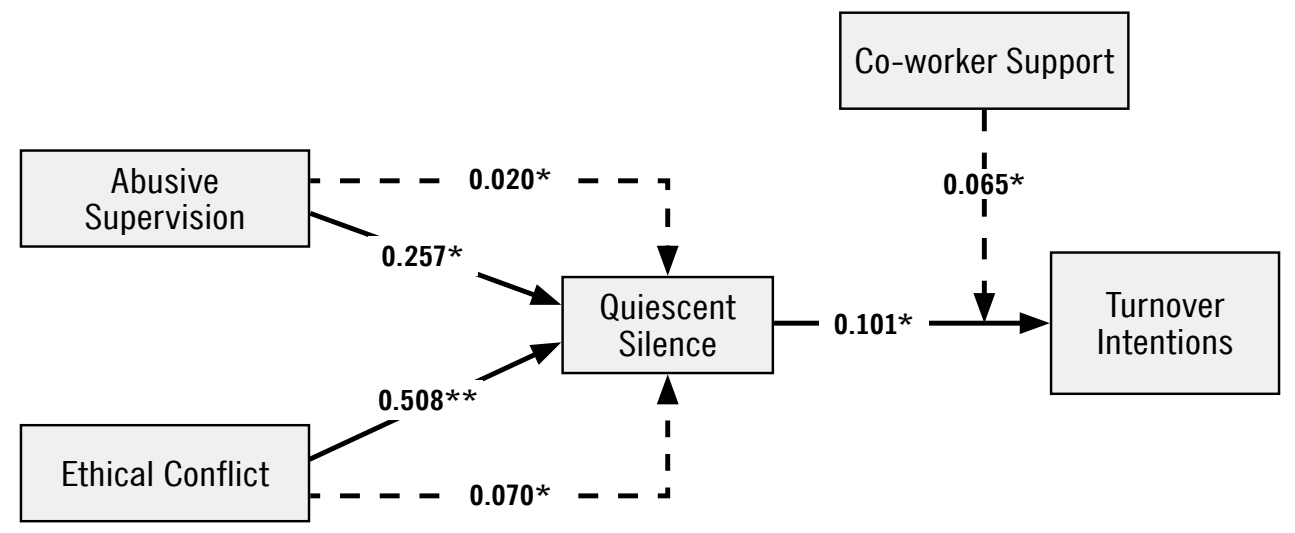

Notes: ${ }^{*} \mathrm{p}<0.01 ;{ }^{*} \mathrm{p}<0.05$.

Source: own elaboration.

\section{Discussion}

The results demonstrate that quiescent silence is a reaction to abusive supervision. The relationship between abusive supervision and quiescent silence is established through the mediating role of fear (Kiewitz et al., 2016), which might be true but the justification of behavioral response (e.g. silence) can be different once compared to emotion (i.e. fear). Based on the SET paradigm, we believe that employees will reciprocate abusive supervision with quiescent silence as a response to aggressive behavior. Similar evidence of reciprocity is noted in previously held studies, i.e. between abusive supervision and employee citizenship behaviors (Rafferty and Restubog, 2011), but also between supervisor abuse and employee deviance at work (Park et al., 2017). More importantly, due to hierarchical differences and authority of the supervisor over subordinates, the employees cannot reciprocate with a similar type of abusive supervision (Lam and $\mathrm{Xu}, 2019$ ). Thus, they prefer to remain silent.

We did not find support for hypotheses 2 and 6, both dealing with perceived injustice. This contradicts the propositions offered by colleagues in already published research studies (Pinder and Harlos, 2001). This contradiction may provide fresh insights into the essence of quiescent silence itself. As defined by Knoll and van Dick (2013), quiescent silence is motivated by fear and, therefore, is a form of protecting oneself against negative personal consequences of speaking up. While abusive supervision and engagement in unethical practices may indeed produce fear (Milliken et al., 2003; Carlson et al., 2012), injustice produces psychological disengagement or withdrawal (Howard 
and Cordes, 2010), not necessarily linked with a desire to protect oneself. This implies that quiescent silence is essentially a form of defense against perceived external threats rather than a reaction to a negative psychological state. Another reason for this finding may be that high power distance may attenuate negative reactions to injustice (Lee et al., 2000; Fisher and Smith, 2006). These results support the relationship between ethical conflict and quiescent silence. Theoretically, individuals reciprocate during social exchanges (Kim, Kim, and Yun, 2015), hence a discrepancy found in interpersonal relationships is perceived as an injustice that can lead to employees withholding information. The individuals living in Russia carry this perception that it is useless to voice opinions, as their suggestions will not be entertained and implemented (Vinogradova and Kozina, 2011), which could have triggered the silence in the first place.

The results further demonstrate that quiescent silence relates to turnover intentions. Previous studies associate negative emotions among employees with their intentions to leave (Cho et al., 2017). Aggressive behaviors at work silence employees when they are emotionally drained and trying to protect their ego (Fast et al., 2014). Since they are emotionally down and not performing well, they quit and change organizations. Such a relationship between quiescent silence and turnover is understandable. The moderating effect of coworker support is found to buffer the relationship between quiescent silence and turnover intentions, which also agrees with previously held studies (Kim et al., 2017). Researchers propose that coworker support normalizes employee emotions that keep them intact and counteract aggressive behaviors. Since Russians work in close collaboration, coworker support is understandable as a reciprocal arrangement. Theoretically, there is evidence that coworker support strengthens pro-environmental attitude (Paillé et al., 2016) and innovation at work (Rehman et al., 2019). Our study provides empirical evidence that coworker support is an important element to prevent employees from leaving organizations. As per the proposed hypotheses, in situations that show high co-worker support, quiescent silence does not lead to turnover intentions. This highlights the important role of co-worker support, as postulated in previously held studies (Kim et al., 2017).

\section{Theoretical Implications}

This study contributes to the literature in three main ways. First, it adds to the growing body of research on antecedents of employee silence, following the calls for exploring more variables that can explain the emergence of quiescent silence (Xu et al., 2015). Our findings indicate that ethical conflict can indeed be conducive to silence, along with abusive supervision. Second, the findings related to the mediating role of quies- 
cent silence contribute to bridging the gap in existent research on the defensive reactions that may trigger employee turnover intentions (Morrison, 2014). Thus, this study makes an important contribution to understanding the determinants of turnover intentions among FLEs. Third, the present study introduces coworker support as a moderator between quiescent silence and turnover intentions, thus opening new avenues for future research on the complex relationships between the variables that affect or mitigate intentions to quit. Research that shows coworker support to reduce the negative consequences of employee silence is scarce. Although moderating effects of coworker support are examined in earlier studies (Kim et al., 2017), its buffering effect between quiescent silence and turnover intentions is unique to this study. Finally, this is the first study to examine abusive supervisory behaviors and perceived injustice in the context of Russia as a high power distance culture.

\section{Managerial Implications}

The employees who intend to quit - i.e. have high turnover intentions - may be less inclined to do their jobs productively and responsibly, and to care about providing a positive customer experience. Therefore, managers must understand antecedents of intentions to quit and signals that can indicate the negative dynamics in turnover intentions. The results of this study reveal that quiescent silence may be one of such initial signals. Therefore, managers should consistently monitor employee silence and consider it an early warning that enables them to act before intentions to quit turn into an actual turnover. They may observe silence in meetings and via employee participation in events at work. A proactive approach can help them in diagnosing silence. Given the detrimental effects of silence, a straightforward approach for managers is to break it deliberately by inquiring and seeking feedback. Managers should provide means for employees to communicate their concerns indirectly while ensuring their anonymity.

Quiescent silence is essentially a defensive behavior motivated by fear that emerges as an effect of abusive supervision and ethical conflict. Therefore, it may be very difficult for the employee to speak up even if required by a direct supervisor. Thus, it is important for organizations to provide channels for employee voice that is otherwise suppressed: ranging from hotlines to opportunities to bring up the issues in a discussion with upper-level managers. In the Russian context of high power distance, breaking silence requires more effort compared to low power distance contexts. This effort should be focused on informal rather than formal mechanisms, to include developing a participative climate (Tangirala and Ramanujam, 2008). 
Silence and the lack of feedback are common issues among employees in Russian organizations (Vinokurova et al., 2017). The core reason that employees are not sharing feedback is their perception that speaking up is useless as the management is not much interested in implementing their suggestions (Vinogradova and Kozina, 2011). There is a need to hold informal sessions with employees - by securing their privacy concerns - to encourage them to voice their opinions (Burke and Cooper, 2013). Moreover, there is a need to understand why supervisors are aggressive as sometimes high-performance standards might contribute to their anxiety (Jensen et al., 2013). On the other hand, organizations should educate employees concerning work standards that they need to maintain. The identification of factors that cause fear is important to explore via both informal and formal meetings so as to minimize chances of silence among FLEs.

\section{Limitations and Future Research}

The first limitation of this research is the specifics of the measures used to collect the data only from employees. We collected data via self-reported measures that produce subjective responses. Although we checked for Harman's one-factor test and assured anonymity of respondents, the sensitive nature of the study can still produce social desirability bias. In line with this limitation, we propose some experimental designs to collect data. Moreover, we collected data only from FLEs working in a Russian healthcare organization due to the difficulty of obtaining dyadic data, as it may require much more time and approvals in a highly bureaucratic system such as Russian organizations. Keeping this in mind, we suggest collecting data both from the FLEs and their managers to extend the study of quiescent silence (Liao et al., 2016).

Second, we collected data via a cross-sectional research design. By employing such designs, researchers cannot examine behavioral changes that happen over time (Levin, 2006). Quiescent silence is not static, and it may change into other forms of silence due to the transformations in organizations (Nohe and Sonntag, 2014). Moreover, supervisory behaviors can change over time (Holtz and Harold, 2013). In this regard, the employment of longitudinal design to study aggression at work might bring interesting insights for managers.

Third, the deductive nature of our study forces us to investigate negative outcomes of abusive supervision, i.e. quiescent silence and turnover intentions. The dominant literature posits abusive supervision as a negative phenomenon resulting in a few negative outcomes such as silence (Xu et al., 2020), the lack of employee engagement (Wang et al., 2020), and employee deviance (Park et al., 2017). However, it would be 
interesting to examine some positive outcomes of abusive supervision. This does not entail a justification of abuse at work, but the idea originates from the relationship between subordinates and their supervisors. This relational identification is scantly examined (Erkutlu and Chafra, 2019). One employee perceives it as abuse while another person might consider it as an opportunity to boost performance. Since abusive supervision is perception-based, several elements can contribute to it, such as employee moods, supervisor-subordinate relationship, and employee personality. All these can be intelligently positioned to extend research. Moreover, researchers should rethink abuse. What constitutes an abuse versus connotations associated with employee development should undergo precise conceptualization.

Fourth, our study is quantitative in nature. The deductive nature of theorizing is common in recently held studies (Xu et al., 2020). However, why, when, and whom supervisors abuse are interesting questions that can extend research in this field. Quiescent silence is conceptualized as a first-order construct, and it is extensively investigated (Pinder and Harlos, 2001). Given its importance to the organizational context, we suggest researchers extend its theoretical breadth. The employment of mixed-methods designs might enrich quiescent silence as a construct. Following this suggestion, some indicate silence in the non-Western context as a sign of wisdom (Mannan and Kashif, 2019), but this has not been conceptualized yet. This wisdom-signaling silence is an exciting area of future inquiry to extend research in employee silence/voice.

\section{References}

Akgunduz, Y. and Eryilmaz, G. (2018). Does turnover intention mediate the effects of job insecurity and co-worker support on social loafing? International Journal of Hospitality Management, 68, 41-49. https://doi.org/10.1016/j.ijhm.2017.09.010.

Bagozzi, R.P., Yi, Y., and Phillips, L.W. (1991). Assessing construct validity in organizational research. Administrative Science Quarterly, 421-458. https://doi.org/10.2307/2393203.

Balabanova, E., Efendiev, A., Ehrnrooth, M., and Koveshnikov, A. (2016). Job satisfaction, blat and intentions to leave among blue-collar employees in contemporary Russia. Baltic Journal of Management, 11(1), 21-43. https://doi.org/10.1108/BJM-03-2015-0079.

Blau, G. (2000). Job, organizational, and professional context antecedents as predictors of intent for interrole work transitions. Journal of Vocational Behavior, 56(3), 330-345.

https://doi.org/10.1006/jvbe.1999.1718.

Bondarouk, T., Bos-Nehles, A., and Hesselink, X. (2016). Understanding the congruence of HRM frames in a healthcare organization. Baltic Journal of Management, 11(1), 2-20. https://doi.org/10.1108/BJM-02-2015-0035.

Brinsfield, C.T., Edwards, M.S., and Greenberg, J. (2009). Voice and silence in organizations: Historical review and current conceptualizations. Voice and silence in organizations, 1. 
Burke, R.J., and Cooper, C.L. (2013). Voice and whistleblowing in organizations: Overcoming fear, fostering courage and unleashing candour: Edward Elgar Publishing.

Cho, Y.-N., Rutherford, B.N., Friend, S.B., Hamwi, G.A., and Park, J. (2017). The Role of Emotions on Frontline Employee Turnover Intentions. Journal of Marketing Theory and Practice, 25(1), 57-68. https://doi.org/10.1080/10696679.2016.1235960.

Chung, Y.W., and Yang, J.Y. (2017). The mediating effects of organization-based self-esteem for the relationship between workplace ostracism and workplace behaviors. Baltic Journal of Management, 12(2), 255-270. https://doi.org/10.1108/BJM-06-2016-0130.

Ciftcioglu, A. (2010). The relationship between perceived external prestige and turnover intention: An empirical investigation. Corporate Reputation Review, 13(4), 248-263. https://doi.org/10.1057/crr.2010.22.

Cohen, A., and Diamant, A. (2017). The role of justice perceptions in determining counterproductive work behaviors. The International Journal of Human Resource Management, 1-24.

Cook, K.S., Cheshire, C., Rice, E.R., and Nakagawa, S. (2013). Social exchange theory Handbook of social psychology (pp. 61-88): Springer. https://doi.org/10.1007/978-94-007-6772-0_3.

Dahling, J.J., Chau, S.L., Mayer, D.M., and Gregory, J.B. (2012). Breaking rules for the right reasons? An investigation of pro-social rule breaking. Journal of Organizational Behavior, 33(1), 21-42. https://doi.org/10.1002/job.730.

De Clercq, D., Azeem, M. U., Haq, I. U., and Bouckenooghe, D. (2020). The stress-reducing effect of coworker support on turnover intentions: Moderation by political ineptness and despotic leadership. Journal of Business Research, 111, 12-24. https://doi.org/10.1016/j.jbusres.2020.01.064.

Dedahanov, A.T., Lee, D., Rhee, J., and Yusupov, S. (2016). An examination of the associations among cultural dimensions, relational silence and stress. Personnel Review, 45(3), 593-604. https://doi.org/10.1108/PR-08-2014-0189.

Ducharme, L.J., and Martin, J.K. (2000). Unrewarding work, coworker support, and job satisfaction: A test of the buffering hypothesis. Work and Occupations, 27(2), 223-243. https://doi.org/10.1177/0730888400027002005.

Dusek, G.A., Clarke, R., Yurova, Y., and Ruppel, C.P. (2016). Employee turnover in international brand hotels in Russia: A comparison of nationals and foreign nationals. Journal of East-West Business, 22(1), 51-75. https://doi.org/10.1080/10669868.2015.1126878.

Erkutlu, H., and Chafra, J. (2019). Leader Machiavellianism and follower silence: the mediating role of relational identification and the moderating role of psychological distance. European Journal of Management and Business Economics, 28(3), 323-342. https://doi.org/10.1108/EJMBE-09-2018-0097.

Fast, N.J., Burris, E.R., and Bartel, C.A. (2014). Managing to stay in the dark: Managerial self-efficacy, ego defensiveness, and the aversion to employee voice. Academy of Management Journal, 57(4), 1013-1034. https://doi.org/10.5465/amj.2012.0393.

Gerbing, D.W., and Anderson, J.C. (1988). An updated paradigm for scale development incorporating unidimensionality and its assessment. Journal of Marketing Research, 186-192. https://doi.org/10.1177/002224378802500207.

Halbesleben, J.R. (2012). Positive coworker exchanges. Personal relationships. The effect on employee attitudes, behavior, and well-being, 107-130.

Harlos, K., and Knoll, M. (2018). Employee Silence and Workplace Bullying. Pathways of Job-related Negative Behaviour, 1-29. https://doi.org/10.1007/978-981-10-6173-8_9-1.

Harris, K.J., Harvey, P., and Kacmar, K.M. (2011). Abusive supervisory reactions to coworker relationship conflict. The Leadership Quarterly, 22(5), 1010-1023.

https://doi.org/10.1016/j.leaqua.2011.07.020. 
Hofstede, G.H., Hofstede, G.J., and Minkov, M. (2005). Cultures and organizations: Software of the mind (Vol. 2). New York: McGraw-Hill.

Hogreve, J., Iseke, A., Derfuss, K., and Eller, T. (2017). The service-profit chain: A meta-analytic test of a comprehensive theoretical framework. Journal of marketing, 81(3), 41-61. https://doi.org/10.1509/jm.15.0395.

Holtz, B.C., and Harold, C.M. (2013). Interpersonal justice and deviance: The moderating effects of interpersonal justice values and justice orientation. Journal of Management, 39(2), 339-365. https://doi.org/10.1177/0149206310390049.

Homans, G.C. (1958). Social behavior as exchange. American journal of sociology, 63(6), 597-606. https://doi.org/10.1086/222355.

Howard, L.W., and Cordes, C.L. (2010). Flight from unfairness: Effects of perceived injustice on emotional exhaustion and employee withdrawal. Journal of Business and Psychology, 25(3), 409-428. https://doi.org/10.1007/s10869-010-9158-5.

Hüffmeier, J., and Hertel, G. (2011). Many cheers make light the work: How social support triggers process gains in teams. Journal of Managerial Psychology, 26(3), 185-204. https://doi.org/10.1108/02683941111112631.

Jensen, J.M., Patel, P.C., and Messersmith, J.G. (2013). High-performance work systems and job control: Consequences for anxiety, role overload, and turnover intentions. Journal of Management, 39(6), 1699-1724. https://doi.org/10.1177/0149206311419663.

Johnson, A., Nguyen, H., Groth, M., and White, L. (2018). Workplace aggression and organisational effectiveness: The mediating role of employee engagement. Australian Journal of Management, 43(4), 614-631. https://doi.org/10.1177/0312896218768378.

Ju, D., Xu, M., Qin, X., and Spector, P. (2018). A Multilevel Study of Abusive Supervision, Norms, and Personal Control on Counterproductive Work Behavior: A Theory of Planned Behavior Approach. Journal of Leadership \& Organizational Studies. https://doi.org/10.1177/1548051818806289.

Kammeyer-Mueller, J.D., Simon, L.S., and Rich, B.L. (2012). The psychic cost of doing wrong ethical conflict, divestiture socialization, and emotional exhaustion. Journal of Management, 38(3), 784-808. https://doi.org/10.1177/0149206310381133.

Kashif, M., Zarkada, A., and Thurasamy, R. (2017). Customer aggression and organizational turnover among service employees. Personnel Review. https://doi.org/10.1108/PR-06-2016-0145.

Khalid, M., Bashir, S., Khan, A.K., and Abbas, N. (2018). When and how abusive supervision leads to knowledge hiding behaviors: An Islamic work ethics perspective. Leadership \& Organization Development Journal, 39(6), 794-806. https://doi.org/10.1108/LODJ-05-2017-0140.

Khan, A.K., Quratulain, S., and Crawshaw, J.R. (2013). The mediating role of discrete emotions in the relationship between injustice and counterproductive work behaviors: A study in Pakistan. Journal of Business and Psychology, 28(1), 49-61. https://doi.org/10.1007/s10869-012-9269-2.

Kiewitz, C., Restubog, S.L.D., Shoss, M.K., Garcia, P.R.J.M., and Tang, R.L. (2016). Suffering in silence: Investigating the role of fear in the relationship between abusive supervision and defensive silence. Journal of Applied Psychology, 101(5), 731. https://doi.org/10.1037/apl0000074.

Kim, Hur, W.-M., Moon, T.-W., and Jun, J.-K. (2017). Is all support equal? The moderating effects of supervisor, coworker, and organizational support on the link between emotional labor and job performance. BRQ Business Research Quarterly, 20(2), 124-136. https://doi.org/10.1016/j.brq.2016.11.002

Kim, Kim, M., and Yun, S. (2015). Knowledge sharing, abusive supervision, and support: A social exchange perspective. Group \& Organization Management, 40(5), 599-624.

https://doi.org/10.1177/1059601115577514. 
Kim, Moon, C.W., and Shin, J. (2018). Linkages between empowering leadership and subjective well-being and work performance via perceived organizational and co-worker support. Leadership \& Organization Development Journal. https://doi.org/10.1108/LODJ-06-2017-0173.

Knoll, M., Hall, R. J., and Weigelt, O. (2019). A longitudinal study of the relationships between four differentially motivated forms of employee silence and burnout. Journal of Occupational Health Psychology, 24(5), 572. https://doi.org/10.1037/ocp0000143.

Knoll, M., and van Dick, R. (2013). Do I hear the whistle...? A first attempt to measure four forms of employee silence and their correlates. Journal of Business Ethics, 113(2), 349-362. https://doi.org/10.1007/s10551-012-1308-4.

Lam, L.W., and Xu, A.J. (2019). Power imbalance and employee silence: The role of abusive leadership, power distance orientation, and perceived organisational politics. Applied Psychology, 68(3), 513-546. https://doi.org/10.1111/apps.12170.

Laschinger, H.K.S., and Fida, R. (2014). A time-lagged analysis of the effect of authentic leadership on workplace bullying, burnout, and occupational turnover intentions. European Journal of work and organizational psychology, 23(5), 739-753. https://doi.org/10.1080/1359432X.2013.804646.

Law, A.K.-W. (2007). Hostility in the context of depression: Testing the relevance of perceived social ranking. University of Waterloo.

Levin, K.A. (2006). Study design III: Cross-sectional studies. Evidence-based Dentistry, 7(1), 24-25. https://doi.org/10.1038/sj.ebd.6400375.

Liao, Z., Peng, A.C., Li, W.-D., and Schaubroeck, J. (2016). Is Abuse Always Bad? A Latent Change Score Approach to Examine Consequences of Abusive Supervision. Paper presented at the Academy of Management Proceedings. https://doi.org/10.5465/ambpp.2016.235.

Long, E.C., and Christian, M.S. (2015). Mindfulness buffers retaliatory responses to injustice: A regulatory approach. Journal of Applied Psychology, 100(5), 1409.

https://doi.org/10.1037/apl0000019.

MacNab, B., Brislin, R., Worthley, R., Galperin, B.L., Jenner, S., Lituchy, T.R., Tiessen, J.H. (2007). Culture and ethics management: Whistle-blowing and internal reporting within a NAFTA country context. International Journal of Cross Cultural Management, 7(1), 5-28. https://doi.org/10.1177/1470595807075167.

Mannan, A., and Kashif, M. (2019). Being abused, dealt unfairly, and ethically conflicting? Quitting occupation in the lap of silence. Asia-Pacific Journal of Business Administration. https://doi.org/10.1108/APJBA-01-2019-0013.

Martinko, M.J., Harvey, P., Brees, J.R., and Mackey, J. (2013). A review of abusive supervision research. Journal of Organizational Behavior, 34(S1). https://doi.org/10.1002/job.1888.

Maslow, A. (1954). Motivation and personality. New York: Harper \& Row.

McGuire, G.M. (2007). Intimate work: A typology of the social support that workers provide to their network members. Work and Occupations, 34(2), 125-147. https://doi.org/10.1177/0730888406297313.

Morrison, E.W. (2014). Employee voice and silence. Annu. Rev. Organ. Psychol. Organ. Behav., 1(1), 1731-97. https://doi.org/10.1146/annurev-orgpsych-031413-091328.

Mustafa, G., and Ali, N. (2019). Rewards, autonomous motivation and turnover intention: Results from a non-Western cultural context. Cogent Business \& Management, 6(1).

https://doi.org/10.1080/23311975.2019.1676090.

Nohe, C., and Sonntag, K. (2014). Work-family conflict, social support, and turnover intentions: A longitudinal study. Journal of Vocational Behavior, 85(1), 1-12.

https://doi.org/10.1016/j.jvb.2014.03.007. 
Paillé, P., Mejía-Morelos, J.H., Marché-Paillé, A., Chen, C.C., and Chen, Y. (2016). Corporate greening, exchange process among co-workers, and ethics of care: An empirical study on the determinants of pro-environmental behaviors at coworkers-level. Journal of Business Ethics, 136(3), 6556-6573. https://doi.org/10.1007/s10551-015-2537-0.

Park, H., Hoobler, J.M., Wu, J., Liden, R. C., Hu, J., and Wilson, M.S. (2017). Abusive Supervision and Employee Deviance: A Multifoci Justice Perspective. Journal of Business Ethics, 11-9.

Pinder, C.C., and Harlos, K.P. (2001). Employee silence: Quiescence and acquiescence as responses to perceived injustice Research in Personnel and Human Resources Management, 3313-3369). Emerald Group Publishing Limited.

Pretsch, J., Ehrhardt, N., Engl, L., Risch, B., Roth, J., Schumacher, S., and Schmitt, M. (2016). Injustice in school and students' emotions, well-being, and behavior: A longitudinal study. Social Justice Research, 29(1), 1119-1138. https://doi.org/10.1007/s11211-015-0234-x.

Rafferty, A.E., and Restubog, S.L.D. (2011). The influence of abusive supervisors on followers' organizational citizenship behaviours: The hidden costs of abusive supervision. British Journal of Management, 22(2), 2702-2785. https://doi.org/10.1111/j.1467-8551.2010.00732.x.

Rai, A., and Agarwal, U.A. (2018). Workplace bullying and employee silence: A moderated mediation model of psychological contract violation and workplace friendship. Personnel Review, 47(1), 226-256. https://doi.org/10.1108/PR-03-2017-0071.

Rainer, J., Schneider, J.K., and Lorenz, R.A. (2018). Ethical dilemmas in nursing: An integrative review. Journal of Clinical Nursing, 27(192-0), 3446-3461. https://doi.org/10.1111/jocn.14542.

Rehman, W.U., Ahmad, M., Allen, M.M., Raziq, M.M., and Riaz, A. (2019). High involvement HR systems and innovative work behaviour: the mediating role of psychological empowerment, and the moderating roles of manager and co-worker support. European Journal of work and organizational psychology, 28(4), 525-535. https://doi.org/10.1080/1359432X.2019.1614563.

Reknes, I., Glambek, M., and Einarsen, S.V. (2020). Injustice perceptions, workplace bullying and intention to leave. Employee Relations: The International Journal.

https://doi.org/10.1108/ER-10-2019-0406.

Richard, O.C., Boncoeur, O.D., Chen, H., and Ford, D.L. (2018). Supervisor abuse effects on subordinate turnover intentions and subsequent interpersonal aggression: The role of power-distance orientation and perceived human resource support climate. Journal of Business Ethics. https://doi.org/10.1007/s10551-018-4019-7.

Saari, T., Melin, H., Balabanova, E., and Efendiev, A. (2017). The job demands and resources as antecedents of work engagement: Comparative research on Finland and Russia. Baltic Journal of Management, 12(2), 240-254. https://doi.org/10.1108/BJM-05-2016-0112.

Schepers, J., and Nijssen, E.J. (2018). Brand advocacy in the frontline: how does it affect customer satisfaction? Journal of Service Management. https://doi.org/10.1108/JOSM-07-2017-0165.

Scott, W., Milioto, M., Trost, Z., and Sullivan, M.J. (2016). The relationship between perceived injustice and the working alliance: a cross-sectional study of patients with persistent pain attending multidisciplinary rehabilitation. Disability and rehabilitation, 38(24), 2365-2373. https://doi.org/10.3109/09638288.2015.1129444.

Shafer, W.E. (2002). Ethical pressure, organizational-professional conflict, and related work outcomes among management accountants. Journal of Business Ethics, 38(3), 2612-73.

Shantz, A., Alfes, K., and Latham, G.P. (2016). The buffering effect of perceived organizational support on the relationship between work engagement and behavioral outcomes. Human Resource Management, 55(1), 253-258. https://doi.org/10.1002/hrm.21653.

Shantz, A., and Booth, J.E. (2014). Service employees and self-verification: The roles of occupational stigma consciousness and core self-evaluations. Human Relations, 67(12), 1439-1465. https://doi.org/10.1177/0018726713519280. 
Shao, R., Rupp, D.E., Skarlicki, D. P., and Jones, K.S. (2013). Employee justice across cultures: A meta-analytic review. Journal of Management, 39(1), 263-301. https://doi.org/10.1177/0149206311422447.

Tangirala, S., and Ramanujam, R. (2008). Employee silence on critical work issues: The cross level effects of procedural justice climate. Personnel Psychology, 61(1), 376-378. https://doi.org/10.1111/j.1744-6570.2008.00105.x.

Tepper, B.J. (2000). Consequences of abusive supervision. Academy of Management Journal, 43(2), 178-190. https://doi.org/10.2307/1556375.

Tian, Q., and Peterson, D.K. (2016). The effects of ethical pressure and power distance orientation on unethical pro-organizational behavior: the case of earnings management. Business Ethics: A European Review, 25(2), 159-171. https://doi.org/10.1111/beer.12109.

Valentine, S., Hollingworth, D., and Eidsness, B. (2014). Ethics-related selection and reduced ethical conflict as drivers of positive work attitudes: Delivering on employees' expectations for an ethical workplace. Personnel Review, 43(5), 692-716. https://doi.org/10.1108/PR-12-2012-0207.

Vemuri, S. (2019). Conceptualising Silence. Managing Silence in Workplaces, 232-239. https://doi.org/10.1108/978-1-78973-445-420191012.

Vinogradova, E., and Kozina, I. (2011). Otnosheniia sotrudnichestva i konflikta v predstavleniiakh rossiiskikh rabotnikov [Relations of Cooperation and Conflict in the Representations of Russian Workers]. Sociological Studies, 9, 304-311.

Vinokurova, N., Boltrukevich, V., and Naumov, A. (2017). 13 Leadership and change management. Leadership and Change Management: A Cross-Cultural Perspective. https://doi.org/10.4324/9781315591766-13.

Wang, C.-C., Hsieh, H.-H., and Wang, Y.-D. (2020). Abusive supervision and employee engagement and satisfaction: the mediating role of employee silence. Personnel Review. https://doi.org/10.1108/ PR-04-2019-0147.

Whiteside, D.B., and Barclay, L.J. (2013). Echoes of silence: Employee silence as a mediator between overall justice and employee outcomes. Journal of Business Ethics, 116(2), 251-266. https://doi.org/10.1007/s10551-012-1467-3.

Xu, Loi, R., and Lam, L.W. (2015). The bad boss takes it all: How abusive supervision and leader-member exchange interact to influence employee silence. The Leadership Quarterly, 26(5), 7637-74. https://doi.org/10.1016/j.leaqua.2015.03.002.

Xu, Martinez, L.R., Van Hoof, H., Tews, M., Torres, L., and Farfan, K. (2018). The impact of abusive supervision and co-worker support on hospitality and tourism student employees' turnover intentions in Ecuador. Current issues in Tourism, 21(7), 775-790. https://doi.org/10.1080/13683500.2015.1076771.

Xu, Zhao, Y., Xi, M., and Li, F. (2020). Abusive supervision, high-performance work systems, and subordinate silence. Personnel Review. https://doi.org/10.1108/PR-01-2019-0029.

Yousaf, A., Sanders, K., and Abbas, Q. (2015). Organizational/occupational commitment and organizational/occupational turnover intentions: A happy marriage? Personnel Review, 44(4), 470-491. https://doi.org/10.1108/PR-12-2012-0203.

Zawadzki, M. (2018). Dignity in the workplace. The perspective of humanistic management. Journal of Management and Business Administration. Central Europe, 26(1), 1711-1788. https://doi.org/10.7206/jmba.ce.2450-7814.224.

Zeidan, S., and Itani, N. (2020). Cultivating Employee Engagement in Organizations: Development of a Conceptual Framework. Central European Management Journal, 28(1), 991-1018. https://doi.org/10.7206/cemj.2658-0845.18. 